\title{
An Architecture for the Agricultural Machinery Intelligent Scheduling in Cross-Regional Work Based on Cloud Computing and Internet of Things
}

\author{
Sun Zhiguo ${ }^{1,2}$, Xia Hui ${ }^{3}$, and Wang Wensheng ${ }^{1,2}$ \\ ${ }^{1}$ Agricultural Information Institute, The Chinese Academy of Agricultural Sciences, \\ Beijing, P.R. China \\ ${ }^{2}$ Key Laboratory of Digital Agricultural Early-warning Technology (2006-2010), \\ Ministry of Agriculture, P.R. China \\ ${ }^{3}$ National Institute for Communicable Disease Control and Prevention, \\ Chinese Center for Disease Control and Prevention, Beijing, P.R. China \\ szg@caas.net.cn
}

\begin{abstract}
The paper introduces the problems in china's agricultural machinery information. We provide an architecture for the agricultural machinery intelligent scheduling in cross-regional work. We put forward constructing the private cloud of agricultural machinery with the aid of cloud computing technology, and forward agricultural machinery will link together through Internet of Things technology. We provide an information platform and simplified it to three components including information service system, communication line and monitoring front-end equipment machine carrying. We also describes two modes to realize the intelligent scheduling function of agricultural machinery cross-regional working.
\end{abstract}

Keywords: Agricultural machinery, Cross-regional work, Intelligent scheduling, Cloud computing, Internet of Things, GPS, Bei-dou.

\section{Introduction}

The agricultural mechanization is a key measure to improve efficiency of agriculture production. The agricultural mechanization of china has grown increasingly, presented a good situation of fast and sound development since 2000. Today, the agricultural machinery with high performance and big power and compound working keeps high speed growth, the structure of agricultural machinery equipment has made a remarkable improvement, and the level of farmland working mechanization has risen considerably.

In recent years, the informationization construction of agricultural machinery has developed to some extent in our country, and information network services are further provided too. But because the informationization construction of agricultural machinery started later in China, the whole level is still lower, there exists differences especially in the development and utilization of agricultural machinery information resource, comparing with developed countries and other domestic industries. The 
negative effects of unrestricted flows of agricultural machines begin to show gradually. The situation of gathering and loss of control may occur sometimes, and cause society instability incidents. The unrestricted flows of agricultural machines are as follows: 1. wasting energy; 2. lower working efficiency; 3 . instability in service prices; 4. increasing traffic pressure; 5 . the damage of fields water conservancy facilities resulted by repeat movement; 6. no farm machines and implements to hire in some remote areas.

We will construct an advanced intelligent scheduling platform for agricultural machinery cross-regional working with advanced communication and information technologies such as Internet, mobile telephone, fixed-line telephone, 3G, GPS, Bei-Dou satellite navigation system, cloud computing and Internet of Things and so on, to implement the guidance and service of administrative departments to agricultural mechanization production, promote the restricted and efficient flows of agricultural machinery, improve the utilization and benefit of agricultural machinery, provide alldirectional services for agricultural machinery users and farm households.

\section{Functions}

The platform can command and dispatch farm machines and implements to execute cross-regional working and accomplish the tasks of tillage and cultivation and harvest according to the factors such as crop mature time, weather, farm machines distribution in different areas of our country. It can realize various functions including inquiry of farm machines position, track review, information reception and release, state monitoring of farm machines, failure remote diagnosis of farm machines, inquiry of maintenance and oil supply sites, and measure of farmland area and estimation of crop yields.

\section{Architecture Design}

\subsection{Design of Overall Information Network Architecture}

We will construct an advanced intelligent scheduling platform consisting of information system, database, users at all levels and farm machines for agricultural machinery cross-regional working. The information system and database will be constructed and monitored uniformly by central government with the aid of cloud computing technology and constructing the private cloud of agricultural machinery, namely agricultural machinery cloud that will control all computing resource of information system and storage resource of database. The system users consist of agricultural mechanization administrative departments from central government to local governments, service organizations of agricultural machinery and agricultural machine users. The agricultural mechanization administrative departments at all levels and service organizations of agricultural machinery can supervise the farm machinery and implements in their areas and realize the intelligent scheduling of cross-regional working by using the information system uniformly. The agricultural machine users can get related scheduling information and all kinds of service information with the system. The trends, static state and other information factors related to agricultural machinery production 
including crop mature time in different areas of our country, farm machines distribution and state, current crop planting and disasters such as drought or waterlog will be stored in the database of agricultural machinery cloud, and the database can get information related to agricultural machinery production by network connecting to the databases of national departments of atmosphere, earthquake monitoring and water conservancy in time. With Internet of Things technology, farm machines and implements in all areas can communicate with datacenter of information service platform in wireless mode by configuration of monitoring front-end equipments machine carrying, and upload all kinds of information such as running state and geographical position automatically.

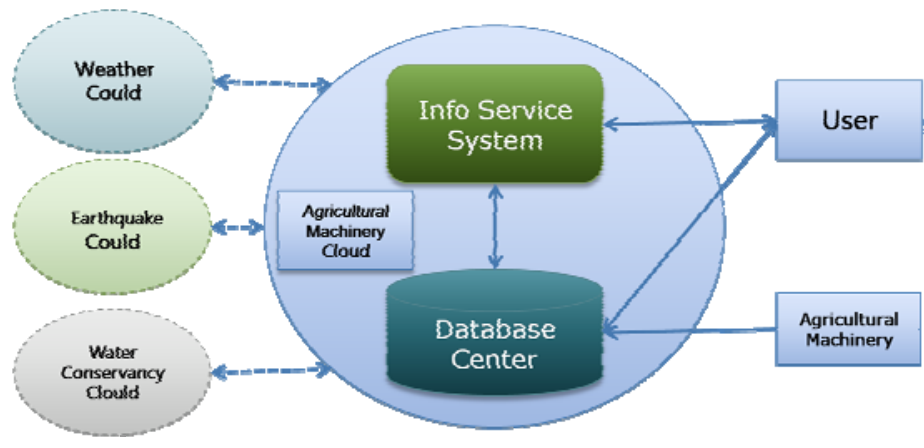

Fig. 1. The information network architecture

The information platform can be simplified to three components including information service system, communication line and monitoring front-end equipment machine carrying.

\subsection{Design of Information Service System}

The customer level of information service system will consist of central system, local classification system, agricultural machinery service organization system and agricultural machine users system.

The central system has two main functional modules which are system maintenance and resource distribution module and intelligent scheduling module of agricultural machinery cross-regional working. The management and maintenance of whole system are taken in charge by central government with the system maintenance and resource distribution module. The intelligent scheduling module of agricultural machinery cross-regional working can command and control farm machines and implements to execute cross-regional working and accomplish the tasks of tillage and cultivation and harvest, realize the functions including inquiry of farm machines position and track review.

The local classification system can be divided into multi-level such as province level, ground level, county level and other higher and lower system according to the detailed condition in different areas. The systems at all levels have the similar functions; the main function module is intelligent scheduling module of agricultural 
machinery cross-regional working that has similar function comparing with the scheduling module in central system.

The agricultural machinery service organization system that is grass-roots organizations of agricultural machinery management mainly comprises two functional modules which are intelligent scheduling module of agricultural machinery cross-regional working and farm machines management module. The function of intelligent scheduling module of agricultural machinery cross-regional working is similar to that of central and local systems. The farm machines management module can provide data management for farm machines in the whole large-scale system. All farm machines registered in system should belong to a certain grass-roots agricultural machinery service organizations in principle, the service organizations should acknowledge and supervise the information validity of farm machines belonging to them.

The agricultural machine users system can mainly provide some scheduling services and additional service automatically. The agricultural machine users or farm households can receive scheduling instructions automatically and answer back, and get some additional service interactively such as location navigation service, farm machines state alarm, failure remote diagnosis of farm machines and inquiry of maintenance and oil supply sites.

\subsection{Design of Communication Lines and Monitoring Front-End Machine Carrying}

The users at all levels can connect to information platform through various Internet connection modes directly. They also can encrypt the data transmitting end-to-end with installation of SSL VPN considering the data confidentiality of the entire system. The devices used to connect to Internet can support all kinds of information terminals, and normal agricultural machine users can utilize the function such as failure remote diagnosis of farm machines by furnishing mobile video terminals such as cell phones.

The farm machines and implements can connect to information platform and upload data by the suggesting three patterns as follow considering different situations of all parts of our country:

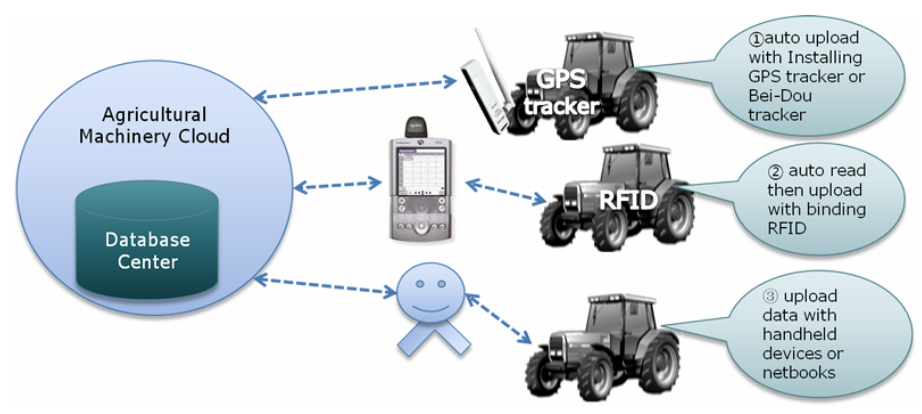

Fig. 2. Three patterns of connect to information platform and upload data 
(1) Installing GPS tracker or Bei-Dou tracker on the farm machines, and machines transmit data to datacenter by mobile network including GPRS, TD, WCDMA. It is the main connection pattern of the platform.

(2) Binding RFID on the farm machines, the agricultural machinery service organizations install mobile RFID reader in the areas in which signals are acceptable, and read the running state data of farm machines terminals needing management in their area of jurisdiction intently, and upload data by mobile network uniformly. The pattern adapts to the group working of farm machines and implements, for example, various farm machines and implements are combined together to form a comprehensive service farm machine group, these farm machines and implements typically move and are supervised uniformly.

(3) The farm machines and implements can upload data with handheld devices or netbooks after getting data manually. The pattern adapts to the farm machines and implements without automatic uploading conditions. It is a good supplement to the first pattern.

The monitoring front-end equipment farm machine carrying is a small scale integration instrument installing on the farm machine, can integrate all kinds of sensors and data collection devices, and upload data automatically. For example, it can integrate GPS or Bei-Dou positioning module to get position information and record the movement tracks of farm machines and implements for intelligent scheduling of cross-regional working; it can integrate video camera to record the working state of farm machine users; it can integrate oil circuit sensor to get oil supply information, and upload data to agricultural machinery cloud, and perform remote computing combining with its movement state to match the oil supply time and best supply sites, then transmit the data to farm machine users as reference; it can integrate key running position sensor to monitor the working state and help making failure diagnosis; it can integrate metered sensor to record farm machines working distance.

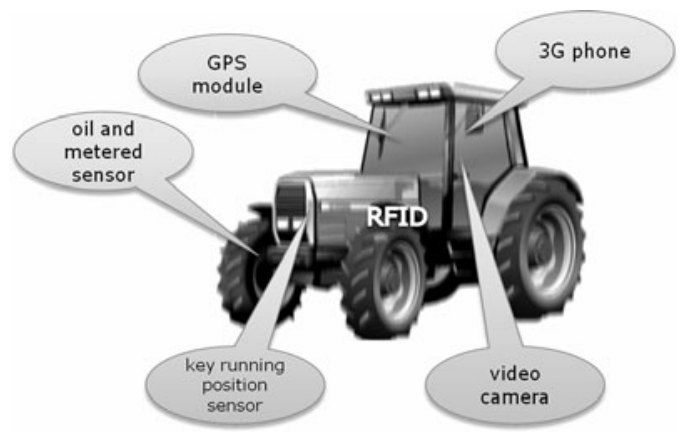

Fig. 3. The monitoring front-end equipment

The front-end equipment machine carrying can send position information and various data of running state to agricultural machinery cloud continuously with Internet of Things in working time of farm machine, and provide decision making references and service information. If data transmission fails and overruns the preset time, the information platform system will automatically alarm and send cell phone message to farm 
machine users by the system, or the operators of agricultural machinery service organizations will contact with users by telephone or other measures to deal with the farm machine.

\subsection{Design of Intelligent Scheduling of Agricultural Machinery Cross-Regional Working}

There are two modes as follows to realize the intelligent scheduling function of agricultural machinery cross-regional working:

The Manual Deployment Mode. The deployment modes of systems at all levels are abstracted to a unified mode that is deployment between higher and lower. The flow chart is as follow:

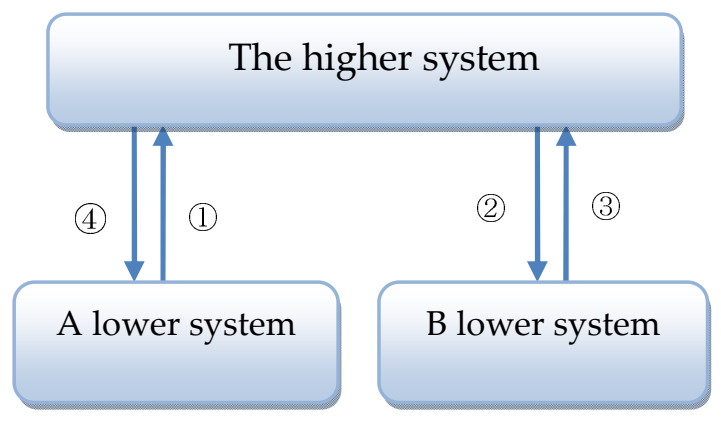

Fig. 4. The manual deployment mode

The meaning of flow chart is as follows:

(1) The lower system of district A requests higher system to deploy farm machines to district A.

(2) The administrative personnel of higher system finds the lower system of district $\mathrm{B}$ has spared farm machines after reviewing the system data collected from all districts, then gives deployment instructions to the lower system of district B, and deploys $\mathrm{X}$ farm machines to district $\mathrm{A}$

(3) The lower system of district B replies to higher system about the details of deployment, and dispatches spared farm machine starting off.

(4) The higher system sends the detailed deployment program to lower system of district A, then the lower system of district A implements the program, the flow of cross-regional deployment comes to an end.

Intelligent study and automatic scheduling mode. Basing on prior consideration of manual deployment mode, the system has a scheduling mode of automatic matching. According to the scheduling requirements proposed by administrators of scheduling centers of system at all levels, the system automatically sends recommended program of automatic matching based on model algorithm to system scheduling centers at all levels considering the factors including weather and mature time, and scheduling administrators of system at all levels make comprehensive judgment according to 
existent experience and issue scheduling instruction. The system also has automatic study function, can correct the scheduling model continuously according to the final scheduling program implemented by scheduling administrators of system at all levels.

To realize the intelligent scheduling model algorithm, the factors including weather and crop mature time should be considered; the smallest distance matrix of all deployment sites and the smallest path matrix relevant should be computed using Floyd algorithm; the tasks are assigned by sweep algorithm; the task routes are sorted by genetic algorithm; the existing research results related to multi-depot vehicle scheduling problem home and abroad need to be studied. The paper focus on architecture research, so do not analyze the detailed algorithm in depth hereon.

Acknowledgements. The work is supported by the Academy of Science and Technology for Development fund project "intelligent search-based Tibet science \& technology information resource sharing technology", the National Science and Technology Major Project of the Ministry of Science and Technology of China (Grant No. 2009ZX03001-019-01), and the special fund project for Basic Science Research Business Fee, AII (No. 2010-J-07).

\section{References}

1. Li, X.-w., Zhang, S.-m., Li, Z.-1.: Agricultural mechanization information network for review and think. Agricultural Equipment \& Technology 154, 4-6 (2009) (in Chinese)

2. Wen, H.-h., Liu, L.-h.: Toward construction of the information to the problems and countermeasures. China Agricultural Machinery Safety Supervision 09, 24-25 (2008) (in Chinese)

3. Zhang, Y., Liu, M.: Propel the development of agriculture mechanical information. Farm Machinery, 124-125 (March 2006) (in Chinese)

4. Ding, W., Liang, C., Xia, M.-h: A Intelligent Public Transportation Scheduling System Based on GPS. China Computer \& Communication, 36-37 (July 2009) (in Chinese)

5. Zhang, Q.-z., Liu, B.-w., Li, J.-t.: Physical Distribution Monitoring System Based on Google Earth. Logistics Technology 206, 200-202 (2009) (in Chinese)

6. Lang, M.-x.: Study on the Model and Algorithm for Multi-Depot Vehicle Scheduling Problem. Journal of Transportation Systems Engineering and Information Technology, 6568 (October 2006) (in Chinese)

7. Zhao, L.-h.: Study on Vehicle Scheduling Model and Algorithm for City Multi-node Delivery. Logistics Technology, 91-93 (August 2007) (in Chinese) 